\title{
Transcriptional blackjack with p21
}

\author{
${\text { Adam } \text { Wood }^{1} \text { and Ali Shilatifard }}^{1,2,3}$ \\ ${ }^{1}$ Department of Biochemistry and ${ }^{2}$ Saint Louis University Cancer Center, Saint Louis University School of Medicine, \\ St. Louis, Missouri 63104, USA
}

Transcriptional regulation by RNA polymerase II (RNA Pol II) is an amalgamated process requiring the collective action of a large number of transcription factors to ensure proper synthesis of messenger RNA (mRNA). Several RNA Pol II elongation factors and proper phosphorylation of the C-terminal domain (CTD) of the RPB1 subunit of Pol II have been shown to be essential for transcription when RNA Pol II enters its processive elongation stage. In a study reported in the previous issue of Genes \& Development, Emerson and colleagues (Gomes et al. 2006) demonstrated an exception to this rule. Transcription of $p 21$, a target gene within the p53 pathway, bypasses the requirements for RNA Pol II elongation factors (including P-TEFb) and CTD phosphorylation for its p53-dependent transcription. Their data indicate the presence of a cellular compensatory mechanism for several of the p53 target genes to ensure a transcriptional response under heightened cellular stress.

Mammalian cells are bombarded with a host of cellular stresses and require specialized mechanisms to maintain their integrity. The p53 protein is a sequence-specific DNA-binding transcription factor that regulates expression of numerous genes involved in cell cycle arrest and apoptosis, and is regarded as the cell's cornerstone of defense against stresses such as DNA damage, oncogene activation, and oxidative stress (Takimoto and El-Deiry 2001; Taylor and Stark 2001).

Several genes involved in the DNA damage response pathway contain p53-binding elements upstream of their promoters. In response to chemical or irradiation-induced DNA damage, binding of p53 to target genes occurs rapidly to shut off cell cycle progression and allow for recovery. There are a variety of p53-dependent pathways that can maintain cell cycle blocks (Bunz et al. 1998; Agami and Bernards 2000; Laronga et al. 2000; Vousden 2000; Gartel and Tyner 2002). Induction of cell cycle arrest by p53 is regulated by the level of transcriptional activation of the $p 21 / W A F 1 / C I P 1$ gene (Espinosa and Emerson 2001; Takimoto and El-Deiry 2001; Espinosa et al. 2003). Once $p 21$ (a potent inhibitor of cyclindependent kinases) is expressed, the cells become arrested (Agami and Bernards 2000). The topoisomerase II

${ }^{3}$ Corresponding author.

E-MAIL shilatia@slu.edu; FAX (314) 977-5737.

Article and publication are at http://www.genesdev.org/cgi/doi/10.1101/ gad.1414506. inhibitor doxorubicin induces double-stranded DNA breaks and is also a potent stimulator of p53 activity (Ravizza et al. 2004). The results presented by Gomes et al. (2006) in the previous issue of Genes \& Development give new insight into the complicated mechanisms cells use to respond to various stresses, and strongly suggest the existence of highly specialized cellular responses that are specific for each type of stress-inducing factor.

\section{p21 transcriptional activation is mediated by p53 in response to DNA damage}

Cells change their transcriptional profile as they respond to cellular stress. Rapid induction of stress response genes requires the assembly and activity of specific transcription factors, while other regions of the genome are repressed until the stress is neutralized. In a recent study, Espinosa et al. used chromatin immunoprecipitation (ChIP) to delineate transcriptional changes at the p21 locus in response to doxorubicin-induced DNA damage (Espinosa et al. 2003). Interestingly, transcription factors found at the $p 21$ locus and throughout the gene differ between DNA damage caused by UV irradiation and the topoisomerase II inhibitor doxorubicin (Espinosa et al. 2003). This indicates that the cellular response is finetuned to the specific nature of the damaging agent via a highly specialized signaling network that differentiates between both the type of stress and the severity of damage that results.

Although the normal cell signaling machinery may not be functional, the cell must immediately activate the transcription of a subset of genes involved in the individual stress response, while simultaneously repressing numerous other genes. It has been demonstrated that long before the presence of a cellular stress, cells have already assembled paused RNA Pol II on the p21 promoter (Espinosa et al. 2003). In response to DNAdamaging agents and p53 activation, the paused, initiating form of RNA Pol II is converted to its elongating form, and transcription of the $p 21$ gene by RNA Pol II rapidly ensues (Espinosa et al. 2003).

\section{A multitude of transcription elongation factors are required for successful mRNA catalysis}

The transcription of protein-coding genes catalyzed by RNA Pol II proceeds through preinitiation, initiation, 
elongation, and termination. Recent studies show RNA Pol II requires the concerted action of several elongation factors for proper synthesis of mRNA following the initiation of transcription. Studies defining mechanisms governing the elongation stage of transcription led to the discovery of a diverse collection of RNA Pol II elongation factors directly regulating elongating Pol II activity. The phosphorylation state of the CTD of RPB1, the largest subunit of Pol II, has been proposed to also play an indispensable role in transcriptional control. Biochemical studies using protein kinase inhibitors such as the nucleotide analog 5,6-dichloro-1- $\beta$-D-ribofuranosylbenzimidazole (DRB) during the process of in vitro transcription have identified other factors involved in the elongation stage of transcription (Marshall and Price 1995; Wada et al. 1998; Shilatifard et al. 2003; Sims et al. 2004). The biochemical fractionation of DRB-sensitive transcription systems has resulted in the identification and purification of a positively acting DRB-sensitive factor, $\mathrm{P}-\mathrm{TEFb}$ (positive transcription elongation factor $\mathrm{b}$ ), and two negatively acting factors, DSIF (DRB sensitivity-inducing factor) and NELF (negative elongation factor). DSIF and NELF can function together to promote RNA Pol II arrest, and P-TEFb can prevent both DSIF- and NELF-dependent RNA Pol II arrest (for reviews, see Shilatifard et al. 2003; Sims et al. 2004).

The cyclin-dependent protein kinase P-TEFb is capable of phosphorylating heptapeptide repeats in the CTD of RNA Pol II. Activity of P-TEFb and other kinases is inhibited by the nucleotide analog DRB. The CTD of Pol II is composed of tandem repeat copies of a heptapeptide with the consensus $\left[\mathrm{Y}_{1} \mathrm{~S}_{2} \mathrm{P}_{3} \mathrm{~T}_{4} \mathrm{~S}_{5} \mathrm{P}_{6} \mathrm{~S}_{7}\right]$. Since the deletion of only a fraction of the heptapeptide repeats within the CTD can be lethal, it was concluded that the CTD is essential for RNA Pol II function (Young 1991). CTD phosphorylation occurs on both Ser 5 and Ser 2 residues. The TFIIH-associated kinase Cdk7/cyclin $\mathrm{H}$ is required for Ser 5 phosphorylation during the transcription initiation and promoter clearance stages of transcription, while Ser 2 phosphorylation by P-TEFb is associated with Pol II engaged in transcript elongation (Shilatifard et al. 2003). Thus, the major CTD kinases CDK7 (TFIIH) and CDK9 (P-TEFb) regulate numerous aspects of transcription by determining the phosphorylation state of the CTD (Zhu et al. 1997; Wada et al. 2000; Zhou et al. 2000; Ramanathan et al. 2001). After UV irradiation, both kinases are activated at the $p 21$ promoter, leading to enhanced RNA Pol II phosphorylation and transcriptional activation of $p 21$ (Espinosa et al. 2003).

The topoisomerase II inhibitor doxorubicin activates the expression of $p 21$ with nearly identical kinetics as UV treatment (Espinosa et al. 2003). In the previous issue of Genes \& Development, Gomes et al. (2006) used highresolution ChIP to study the assortment of transcription factors recruited to the $p 21$ locus during various cellular stresses. Using doxorubicin and the P-TEFb inhibitor DRB (Marshall and Price 1995; Wada et al. 1998), Gomes et al. have uncovered vastly different response mechanisms that ultimately result in p21 activation. Interestingly, p21 transcription can occur normally in DRB- treated cells, indicating that Ser 2 phosphorylation of the CTD is dispensable for $p 21$ activation. Thus, Gomes and colleagues demonstrated that DRB-treated cells accomplish p21 activation and cell cycle arrest when "normal" mechanisms of transcription are inhibited. These findings uncover a fascinating mechanism whereby cells forego normal transcriptional patterns to deal with stress.

A variety of transcription factors are present at the $p 21$ locus in response to DNA damage, but not all are required for its transcription

A large number of RNA Pol II-associated factors influence the kinetic properties of polymerase during its transcription cycle through transient or enduring associations with Pol II. Several components of the RNA Pol II preinitiation complex (PIC) are poised at the $p 21$ proximal promoter prior to induction (i.e., TBP, TFIIH, and hypophosphorylated Pol II) (Fig. 1; Espinosa et al. 2003). Gomes et al. (2006) identified several other factors in-

A

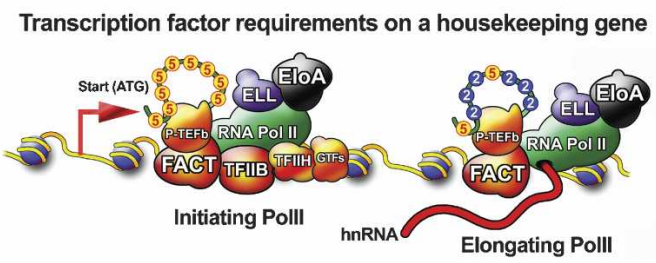

B

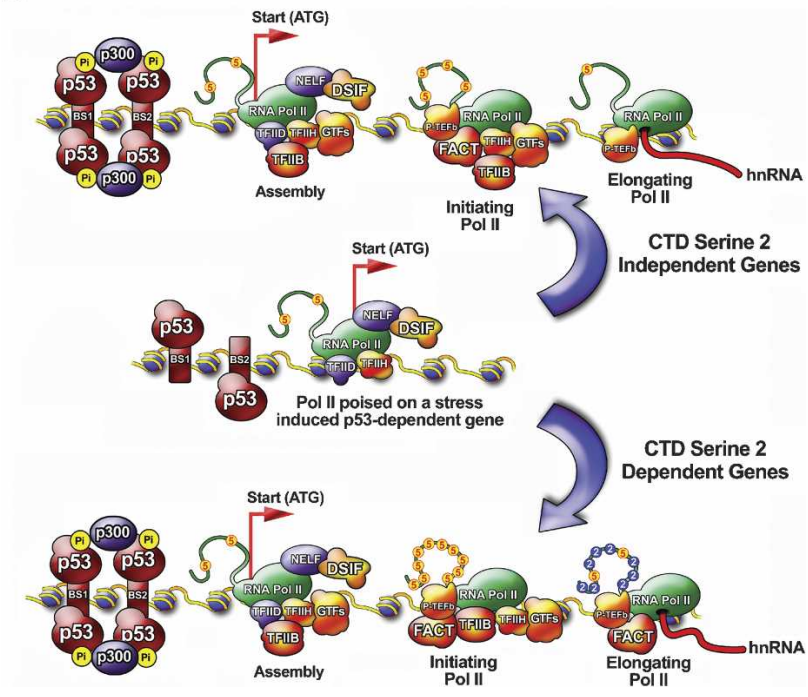

Figure 1. The regulation of gene expression during heightened cellular stress. (A) The repertoire and the requirements for transcription factors on a housekeeping gene not dependent on p53. ( $B$, bottom portion) Some stress-induced p53-dependent genes require the presence of CTD phosphorylation on Ser 2 and Ser 5 within the heptapeptide repeat, as well as the presence of RNA Pol II elongation factors such as FACT. (Upper portion) Gomes et al. (2006) demonstrated that other stress-induced p53-dependent genes such as p21 can bypass the requirement for CTD phosphorylation and the presence of several known RNA Pol II elongation factors. 
volved in p21 activation by increasing both the resolution of the ChIP method and the repertoire of antibodies. While doxorubicin does not alter the amount of TFIID (measured using antibodies against TBP and TAF1) bound to the $p 21$ locus, there is a dramatic increase in the association of TFIIB, RAP74 (TFIIF), Spt5 (DSIF), CDK9 (P-TEFb), CDK7 (TFIH), and SPT16 (FACT) with the proximal promoter and early coding regions. Interestingly, the levels of NELF-A, a component of the transcriptional inhibitor NELF complex, remain elevated at the p21 promoter before and during doxorubicin treatment. This suggests that NELF may play a role in the promoter proximal pausing of RNA Pol II observed at the p21 promoter (Fig. 1). Therefore, the concomitant recruitment of TFIIH, DSIF, and P-TEFb to the same regions within the $p 21$ promoter allows for escape by Pol II and the beginning of the processive elongation stage of p21 transcription.

Gomes et al. (2006) also demonstrated that the distribution of DSIF and P-TEFb mimic levels of polymerase found within the p21coding region of doxorubicintreated cells. While DSIF is highly enriched in the promoter region, P-TEFb levels noticeably increase just after the transcriptional start site (+182 base pairs), indicating that P-TEFb is loaded onto Pol II outside the promoter region. Additionally, Gomes and colleagues suggested that the transcription elongation factor FACT begins its association with Pol II at approximately the same region as P-TEFb and remains bound throughout the entire coding region. These data support the finding that FACT acts synergistically with P-TEFb to relieve DSIF-NELF transcriptional repression (Wada et al. 1998, 2000). However, the loss of Ser 2 phosphorylation on the CTD results in dissociation of FACT with the elongating form of RNA Pol II. Interestingly, the substantial reduction in the levels of FACT in response to DRB does not alter $p 21$ transcription (Fig. 1).

\section{DRB treatment induces $p 21$ expression in the absence of P-TEFb function}

The nucleotide analog DRB is a potent inhibitor of PTEFb (as well as other CDKs) (Marshall and Price 1992, 1995). DRB treatment can activate p53-mediated signaling similar to doxorubicin treatment, but $p 21$ expression is not as robust. By creating a stress-specific transcriptional program, cells can activate p53 target genes when $\mathrm{P}-\mathrm{TEFb}$ and overall transcription are compromised. While some p53 target genes such as p21 and the proapoptotic gene PUMA /Chipuk et al. 2005; Vousden 2005) are up-regulated, others like $14-3-3 \sigma$ and DR5/ Killer (a DNA damage-induced p53-dependent gene) (Wu et al. 1997) become repressed during DRB treatment. These same genes are all up-regulated by doxorubicin treatment, exemplifying the cell's ability to fine-tune a stress response based on the degree and type of insult.

During DRB treatment, the localization of p53, RNA Pol II, and CDK9 (P-TEFb) are similar to doxorubicintreated cells, although there is a striking total loss of Ser 2-phosphorylated RNA Pol II at the p21 locus. Ser 5 phosphorylation is also affected during DRB treatment, and it appears that Ser 5 phosphorylation is removed by the time polymerase reaches the mid-body of $p 21$. As previously mentioned, FACT levels are also drastically reduced at the $p 21$ locus upon DRB treatment. The removal of Ser 2 phosphorylation does not appear to hamper RNA Pol II's ability to carry out p21 transcription. Not only is $p 21$ efficiently transcribed during DRB treatment, but the mRNA is properly processed and polyadenylated. In yeast, total loss of Ser 2 phosphorylation by Ctk 1 results in aberrant 3 '-end processing and recruitment of polyadenylation factors (Ahn et al. 2004). Similar studies in mammalian systems implicate the CTD of Pol II in the proper recruitment of $3^{\prime}$ mRNA processing enzymes (McCracken et al. 1997). Transcript length and proper processing of $p 21 \mathrm{mRNA}$ are unaffected in both doxorubicin- and DRB-treated cells. Polyadenylation of another gene outside the p53-p21 response pathway (HPRT) has significant 3 ' -end processing defects in DRBtreated cells, indicating that while the formation of some cellular transcripts can be affected by DRB and doxorubicin, the mRNAs corresponding to essential stress response enzymes are somehow able to be properly transcribed and processed (Fig. 1). As Gomes et al. (2006) poignantly state, this mechanism "allows cells to mount a transcriptional response to certain types of stress even when global mRNA synthesis is inhibited."

\section{A role for histone methylation in p53-mediated stress-induced $p 21$ transcription}

Cyclin-dependent kinases, such as the Bur1/Bur2 complex and Ctk $1 / 2 / 3$ complex in yeast, play essential roles in histone $\mathrm{H} 3$ methylation on Lys 4 and Lys 36 by COMPASS and Set2, respectively (Xiao et al. 2003; Wood et al. 2005). Bur1/Bur2 functions by regulating recruitment of the Pafl complex and activity of Rad6/Bre1 in monoubiquitination of histone $\mathrm{H} 2 \mathrm{~B}$ (which signals for H3K4 methylation by COMPASS) (Dover et al. 2002; Krogan et al. 2003a; Wood et al. 2003, 2005). Ctk1/2/3 functions by controlling the association of Set 2 with the elongating Pol II, thereby regulating H3K36 methylation on the body of a transcribed gene (Krogan et al. 2003b; Xiao et al. 2003). Since both Bur1/Bur2 and the Ctk1/2/3 complexes in yeast are considered to be related to P$\mathrm{TEFb}$ in humans and the pathway of histone methylation via Rad6/Brel and COMPASS is highly conserved from yeast to human (Tenney and Shilatifard 2005), it is of great interest to determine whether P-TEFb is also required for proper histone methylation in mammalian cells. If so, the following two questions arise: (1) Would such patterns of methylation be required for proper gene expression in mammals? (2) Would p21 gene expression in response to DNA damage or other cellular stresses follow such requirements?

The data presented by Gomes et al. (2006) represent a novel hypothesis that not all genes transcribed by RNA Pol II require the same set of transcription elongation factors. The authors clearly establish that specific p53 target genes such as $p 21$ are rapidly activated in the ab- 
sence of CDK9 (P-TEFb) activity (Fig. 1). Loss of CDK9 activity is followed by a substantial decrease in the association of other essential Pol II elongation factors such as FACT; however, $p 21$ gene expression is not altered in their absence. Recently, several RNA Pol II elongation factors, such as ELL and Elongin A, were found to be required for proper cellular response to heat shock (Gerber et al. 2005). It will be interesting to uncover whether such Pol II elongation factors that regulate the elongation stage of transcription are required for proper $p 21$ gene expression.

Uncovering the existence of transcriptional mechanisms allowing cells to respond to stress in the absence of global mRNA synthesis is a major breakthrough. Future biochemical, genetic, and biological studies defining factor requirements for other genes containing paused polymerases will further our understanding of the molecular mechanism of stress-induced transcriptional regulation.

\section{Acknowledgments}

We thank Kristy Wendt and Dr. Joseph Baldassare for editorial assistance and critical reading of this review. The work in Shilatifard's laboratory is supported by grants from the National Institutes of Health (2R01CA089455 and 1R01GM069905) and the American Cancer Society. A.W. is supported by a American Heart Association predoctoral fellowship. A.S. is a Scholar of the Leukemia and Lymphoma Society.

\section{References}

Agami, R. and Bernards, R. 2000. Distinct initiation and maintenance mechanisms cooperate to induce G1 cell cycle arrest in response to DNA damage. Cell 102: 55-66.

Ahn, S.H., Kim, M., and Buratowski, S. 2004. Phosphorylation of Serine 2 within the RNA polymerase II C-terminal domain couples transcription and $3^{\prime}$ end processing. Mol. Cell 13: $67-76$.

Bunz, F., Dutriaux, A., Lengauer, C., Waldman, T., Zhou, S., Brown, J.P., Sedivy, J.M., Kinzler, K.W., and Vogelstein, B. 1998. Requirement for $\mathrm{p} 53$ and $\mathrm{p} 21$ to sustain G2 arrest after DNA damage. Science 282: 1497-1501.

Chipuk, J.E., Bouchier-Hayes, L., Kuwana, T., Newmeyer, D.D., and Green, D.R. 2005. PUMA couples the nuclear and cytoplasmic proapoptotic function of p53. Science 309: 17321735.

Dover, J., Schneider, J., Tawiah-Boateng, M.A., Wood, A., Dean, K., Johnston, M., and Shilatifard, A. 2002. Methylation of histone $\mathrm{H} 3$ by COMPASS requires ubiquitination of histone H2B by Rad6. J. Biol. Chem. 277: 28368-28371.

Espinosa, J.M. and Emerson, B.M. 2001. Transcriptional regulation by 553 through intrinsic DNA/chromatin binding and site-directed cofactor recruitment. Mol. Cell 8: 57-69.

Espinosa, J.M., Verdun, R.E., and Emerson, B.M. 2003. p53 functions through stress- and promoter-specific recruitment of transcription initiation components before and after DNA damage. Mol. Cell 12: 1015-1027.

Gartel, A.L. and Tyner, A.L. 2002. The role of the cyclin-dependent kinase inhibitor $\mathrm{p} 21$ in apoptosis. Mol. Cancer Ther. 1: 639-649.

Gerber, M., Tenney, K., Conaway, J.W., Conaway, R.C., Eissenberg, J.C., and Shilatifard, A. 2005. Regulation of heat shock gene expression by RNA polymerase II elongation factor, elongin A. J. Biol. Chem. 280: 4017-4020.

Gomes, N.P., Bjerke, G., Llorente, B., Szostek, S.A., Emerson, B.M., and Espinosa, J.M. 2006. Gene-specific requirement for $\mathrm{P}-\mathrm{TEFb}$ activity and RNA polymerase II phosphorylation within the p53 transcriptional program. Genes \& Dev. 20: 601-612.

Krogan, N.J., Dover, J., Wood, A., Schneider, J., Heidt, J., Boateng, M.A., Dean, K., Ryan, O.W., Golshani, A., Johnston, M., et al. 2003a. The Paf1 complex is required for histone H3 methylation by COMPASS and Dotlp: Linking transcriptional elongation to histone methylation. Mol. Cell 11: 721-729.

Krogan, N.J., Kim, M., Tong, A., Golshani, A., Cagney, G., Canadien, V., Richards, D.P., Beattie, B.K., Emili, A., Boone, C., et al. 2003b. Methylation of histone H3 by Set2 in Saccharomyces cerevisiae is linked to transcriptional elongation by RNA polymerase II. Mol. Cell. Biol. 23: 4207-4218.

Laronga, C., Yang, H.-Y., Neal, C., and Lee, M.-H. 2000. Association of the cyclin-dependent kinases and 14-3-3 $\sigma$ negatively regulates cell cycle progression. J. Biol. Chem. 275: 23106-23112.

Marshall, N.F. and Price, D.H. 1992. Control of formation of two distinct classes of RNA polymerase II elongation complexes. Mol. Cell. Biol. 12: 2078-2090.

. 1995. Purification of P-TEFb, a transcription factor required for the transition into productive elongation. J. Biol. Chem. 270: 12335-12338.

McCracken, S., Fong, N., Yankulov, K., Ballantyne, S., Pan, G., Greenblatt, J., Patterson, S.D., Wickens, M., and Bentley, D.L. 1997. The C-terminal domain of RNA polymerase II couples mRNA processing to transcription. Nature 385: 357-361.

Ramanathan, Y., Rajpara, S.M., Reza, S.M., Lees, E., Shuman, S., Mathews, M.B., and Pe'ery, T. 2001. Three RNA polymerase II carboxyl-terminal domain kinases display distinct substrate preferences. J. Biol. Chem. 276: 10913-10920.

Ravizza, R., Gariboldi, M., Passarelli, L., and Monti, E. 2004. Role of the p53/p21 system in the response of human colon carcinoma cells to Doxorubicin. BMC Cancer 4: 92.

Shilatifard, A., Conaway, R.C., and Conaway, J.W. 2003. The RNA polymerase II elongation complex. Annu. Rev. Biochem. 72: 693-715.

Sims III, R.J., Belotserkovskaya, R., and Reinberg, D. 2004. Elongation by RNA polymerase II: The short and long of it. Genes \& Dev. 18: 2437-2468.

Takimoto, R. and El-Deiry, W.S. 2001. DNA replication blockade impairs p53-transactivation. Proc. Nat1. Acad. Sci. 98: 781-783.

Taylor, W.R. and Stark, G.R. 2001. Regulation of the G2/M transition by p53. Oncogene 20: 1803-1815.

Tenney, K. and Shilatifard, A. 2005. A COMPASS in the voyage of defining the role of trithorax/MLL-containing complexes: Linking leukemogenesis to covalent modifications of chromatin. J. Cell. Biochem. 95: 429-436.

Vousden, K.H. 2000. p53: Death star. Cell 103: 691-694.

- 2005. APOPTOSIS: p53 and PUMA: A deadly duo. Science 309: 1685-1686.

Wada, T., Takagi, T., Yamaguchi, Y., Watanabe, D., and Handa, H. 1998. Evidence that P-TEFb alleviates the negative effect of DSIF on RNA polymerase II-dependent transcription in vitro. EMBO J. 17: 7395-7403.

Wada, T., Orphanides, G., Hasegawa, J., Kim, D.-K., Shima, D., Yamaguchi, Y., Fukuda, A., Hisatake, K., Oh, S., Reinberg, D., et al. 2000. FACT relieves DSIF/NELF-mediated inhibition of transcriptional elongation and reveals functional dif- 
ferences between P-TEFb and TFIIH. Mol. Cell 5: 1067-1072.

Wood, A., Schneider, J., Dover, J., Johnston, M., and Shilatifard, A. 2003. The Pafl complex is essential for histone monoubiquitination by the Rad6-Brel complex, which signals for histone methylation by COMPASS and Dotlp. I. Biol. Chem. 278: 34739-34742.

. 2005. The Bur1/Bur2 complex is required for histone H2B monoubiquitination by Rad6/Bre1 and histone methylation by COMPASS. Mol. Cell 20: 589-599.

Wu, G.S., Burns, T.F., McDonald III, E.R., Jiang, W., Meng, R., Krantz, I.D., Kao, G., Gan, D.D., Zhou, J.Y., Muschel, R., et al. 1997. KILLER/DR5 is a DNA damage-inducible p53-regulated death receptor gene. Nat. Genet. 17: 141-143.

Xiao, T., Hall, H., Kizer, K.O., Shibata, Y., Hall, M.C., Borchers, C.H., and Strahl, B.D. 2003. Phosphorylation of RNA polymerase II CTD regulates H3 methylation in yeast. Genes \& Dev. 17: 654-663.

Young, R.A. 1991. RNA polymerase II. Annu. Rev. Biochem. 60: 689-715.

Zhou, M., Halanski, M.A., Radonovich, M.F., Kashanchi, F., Peng, J., Price, D.H., and Brady, J.N. 2000. Tat modifies the activity of CDK9 to phosphorylate serine 5 of the RNA polymerase II carboxyl-terminal domain during human immunodeficiency virus type 1 transcription. Mol. Cell. Biol. 20: 5077-5086.

Zhu, Y., Pe'ery, T., Peng, J., Ramanathan, Y., Marshall, N., Marshall, T., Amendt, B., Mathews, M.B., and Price, D.H. 1997. Transcription elongation factor P-TEFb is required for HIV-1 Tat transactivation in vitro. Genes \& Dev. 11: 2622-2632. 


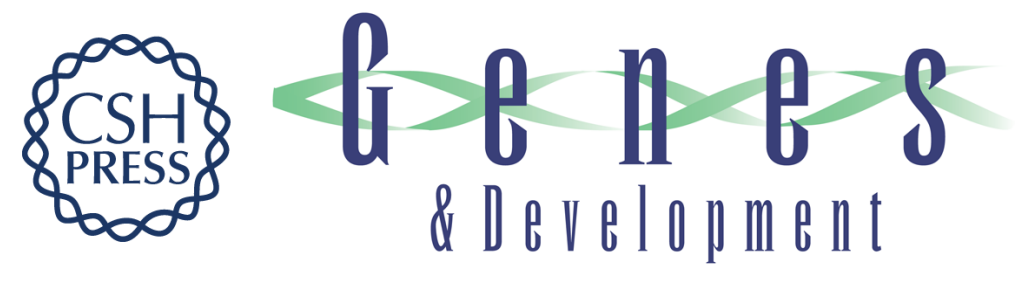

\section{Transcriptional blackjack with p21}

Adam Wood and Ali Shilatifard

Genes Dev. 2006, 20:

Access the most recent version at doi:10.1101/gad.1414506

\section{Related Content Gene-specific requirement for P-TEFb activity and RNA polymerase II phosphorylation within the p53 transcriptional program Nathan P. Gomes, Glen Bjerke, Briardo Llorente, et al. Genes Dev. March , 2006 20: 601-612}

References This article cites 34 articles, 19 of which can be accessed free at: http://genesdev.cshlp.org/content/20/6/643.full.html\#ref-list-1

Articles cited in:

http://genesdev.cshlp.org/content/20/6/643.full.html\#related-urls

\section{License}

Email Alerting

Service

Receive free email alerts when new articles cite this article - sign up in the box at the top right corner of the article or click here.

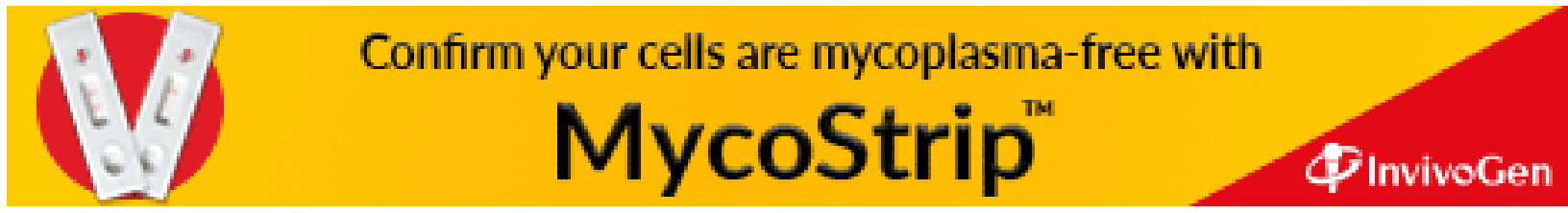

